\title{
COACHING AND MENTORING \\ FOR ACADEMIC DEVELOPMENT
}

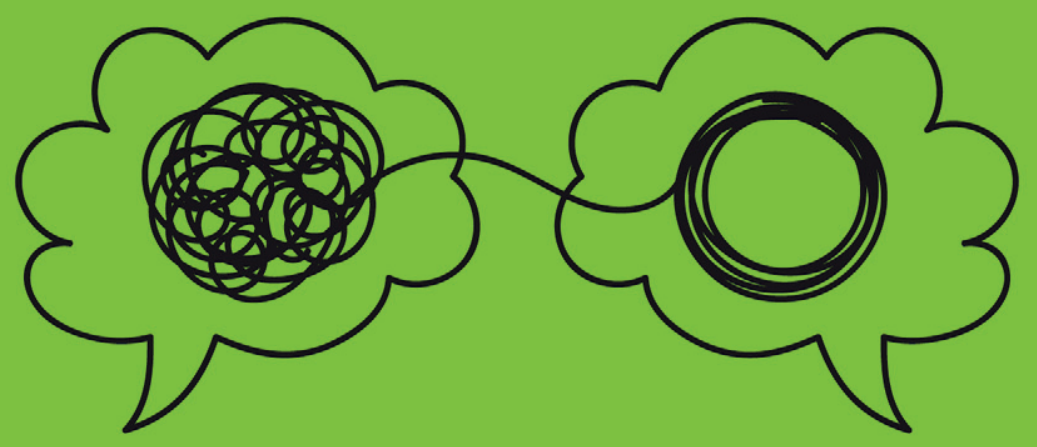

KAY GUCCIONE STEVE HUTCHINSON 


\section{COACHING AND MENTORING FOR ACADEMIC DEVELOPMENT}


Surviving and Thriving in Academia provides short, accessible books for navigating the many challenges, responsibilities and opportunities of academic careers. The series is particularly dedicated to supporting the professional journeys of early and mid-career academics and doctoral students, but will present books of use to scholars at all stages in their careers. Books within the series draw on real-life examples from international scholars, offering practical advice and a supportive and encouraging tone throughout.

Series Editor: Marian Mahat, The University of Melbourne, Australia

In this series:

Achieving Academic Promotion

Edited by Marian Mahat, The University of Melbourne \& Jennifer Tatebe, University of Auckland

Getting the Most Out of Your Doctorate: The Importance of Supervision, Networking and Becoming a Global Academic Edited by Mollie Dollinger, La Trobe University, Australia Forthcoming in the series:

Women Thriving in Academia

Edited by Marian Mahat, The University of Melbourne 
Praise for Coaching and Mentoring for Academic Development

'Guccione and Hutchison not only show that universities can provide solid support for their staff, but also that principled and wellgrounded coaching and mentoring is integral to more equitable employment practices. Highly recommended'.

-Pat Thomson, Professor of Education, The University of Nottingham, UK

'This is an astute, evidence-based handbook that's enjoyable to read and very welcome for both professional staff and academics whose roles involve supporting scholars (emerging or established). The need for precisely this kind of flexible, savvy resource is high! Guccione and Hutchinson have extensive experience of the higher education sector and academic development, and their ability to synthesise complex ideas into clear, compelling guidance for practical strategies is gold'.

-Dr Tseen Khoo, La Trobe University, Australia / The Research Whisperer 
This page intentionally left blank 


\title{
COACHING AND MENTORING FOR ACADEMIC DEVELOPMENT
}

\author{
BY \\ KAY GUCCIONE \\ Glasgow Caledonian University, UK \\ STEVE HUTCHINSON
}

Hutchinson Training and Development, UK

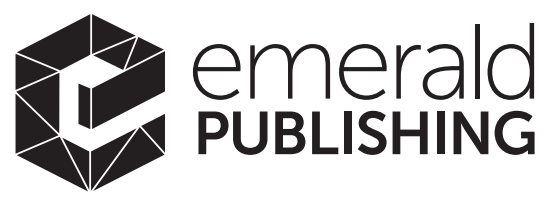

United Kingdom - North America - Japan - India Malaysia - China 
Emerald Publishing Limited

Howard House, Wagon Lane, Bingley BD16 1WA, UK

First edition 2021

(C) 2021 Kay Guccione and Steve Hutchinson

Published under Exclusive License by Emerald Publishing Limited.

Reprints and permissions service

Contact: permissions@emeraldinsight.com

No part of this book may be reproduced, stored in a retrieval system, transmitted in any form or by any means electronic, mechanical, photocopying, recording or otherwise without either the prior written permission of the publisher or a licence permitting restricted copying issued in the UK by The Copyright Licensing Agency and in the USA by The Copyright Clearance Center. Any opinions expressed in the chapters are those of the authors. Whilst Emerald makes every effort to ensure the quality and accuracy of its content, Emerald makes no representation implied or otherwise, as to the chapters' suitability and application and disclaims any warranties, express or implied, to their use.

British Library Cataloguing in Publication Data

A catalogue record for this book is available from the British Library

ISBN: 978-1-78973-910-7 (Print)

ISBN: 978-1-78973-907-7 (Online)

ISBN: 978-1-78973-909-1 (Epub)

ISOQAR certified

Management System,

awarded to Emerald

for adherence to

Environmental

standard

ISOQAR

ISO 14001:2004.

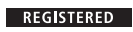

Certificate Number 1985

ISO 14001

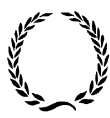

INVESTOR IN PEOPLE 


\section{CONTENTS}

Acknowledgements $\quad$ ix

Introduction to the Book xi

\section{Section 1}

1. Coaching and Mentoring: Concepts and Terminologies Explored

2. Contextualising Mentoring and Coaching Examining the Role of Universities and Higher Education

3. The Academic Context for Mentoring and Coaching

4. A Doctorate is No Longer Enough

5. Situating Mentoring and Coaching within Educational Practice

6. Placing the Focus on Planning, Not Problems

7. Building Repertories of Practice 'Beyond Advice'

8. Amplifying the Learner's Voice

9. What Makes a Good Coaching Question?

10. Using a Coaching Style as Principal Investigator, Supervisor or Manager

\section{Section 2}

11. Creating Agreement and Alignment 91

12. Giving and Receiving Feedback: Coaching Style 99

13. Supporting through Change and Transitions 111 
14. Supporting Personal Development Planning

15. Enabling Efficiency and Effectiveness

16. Building Productive Writing Habits

17. Shaping and Managing Working Relationships

18. Gaining First Funding and Research Independence

19. Mentoring Career Changers

20. Developing Leadership Capabilities

21. Sustaining Change Over Time

22. Supporting Stressed Colleagues

\section{Section 3}

23. Designing and Launching a Mentoring Programme

24. The Reputation of Coaching and Mentoring

25. Aligning Your Programme with Humanistic Principles

26. Designing a Workshop: Orientation to Practice

27. How to Recruit, Retain and Develop Your Coaches and Mentors

28. Enhancing Practice through Peer Conversations

29. Matching Mentoring and Coaching Pairs

30. Anticipating Disengagement from Mentoring and Coaching

31. Evaluating Mentoring and Coaching

32. An Institutional Code of Practice 281

33. How to Find and Recruit Your Own Mentor? 287 Concluding Thoughts 


\section{ACKNOWLEDGEMENTS}

There are two significant people I want to acknowledge as having had a transformative effect on my own career in coaching and mentoring. I reached out to Dr Paul Stokes for help in the early phases of being tasked with setting up a mentoring programme. His support, encouragement and ethos of 'not fostering dependency' gave me a rounded education in the practices of mentoring and coaching, I still draw on ideas I learned from Paul when developing mentors. His prompting also catalysed two essential pivots, the first to get up the confidence to take on delivering mentor workshops myself, and the second to formalise my development by enrolling on a Masters Degree in Coaching, Mentoring and Leadership Development. The superbly skilled Rose Schofield taught me for three years as I completed my Masters, she introduced me to the idea of 'teaching in a coaching style' building relationships of trust with her students. Central to my learning with Rose over the years, as her student, and then as her colleague, was to understand why her approach to teaching and in particular to feedback was so effective at motivating people to learn. Rose does this of course by asking important questions. She asked me questions about my work and practice as a coach that I myself wanted to know the answer to. I adopted and have continued to use many practices learned from Rose, most notably knowing when the 
ethical practitioner of coaching will say no to an idea or request. Taken together, these two mentors have shaped my career and indeed my approach to life. - Kay Guccione

There are a number of good people who've - unknowingly or unwittingly - acted as an informal mentor to me over the years. Some of them I've acknowledged in previous books; people like Geoff Parker and Mike Rawlins to whom I continue to be grateful for their coach-like behaviours and examples. More recently, my colleagues Emma Ford and Paul Toombs have, in their own skilled ways, coached, questioned and influenced my approaches and practices, and for this I will forever be indebted. Thank you also to the team at Chapel House, who showed me light in a very dark tunnel. Finally, thanks to Helen Lawrence, for your questions and ideas and our conversations over cheese on toast. - Steve Hutchinson 


\section{INTRODUCTION TO THE BOOK}

\section{WHAT IS THIS BOOK ABOUT?}

This book covers in detail how you can make full use of coaching conversations to support and develop people who work in universities. The people that you aim to develop may be academic staff, both those with secure employment contracts and those more precariously employed as research associates or technical staff attached to fixed term funding. They may be doctoral researchers, who, whilst they are not always classed as university staff, work hard within and for our universities and contribute greatly to our research and teaching agendas throughout their degrees. You may want to develop the staff who manage our core facilities or manage Departments, running complex projects, and ensuring that the bins are emptied and the lights stay on. Or you may be seeking to make use of mentoring conversations to support the learning and development of the huge range of specialist professional staff who contribute their expertise as librarians, academic developers, careers advisors, counsellors, grant capture managers, strategic planners, welfare advisors and the hundreds of other essential functions of a university. 
Whomever the individual, mentoring brings a powerful opportunity for them to connect to colleagues, talk things through, navigate the demands of their role, seek other perspectives and find their own best way forward. Whether the individual seeking development fits into one of the above groups of university workers, or into several or none, this book will allow you to take a person-centred, inclusive approach to supporting their development. It will enable you to think through the needs of the people you want to develop and to design your mentoring or coaching approach in a systematic way. We present here a practical guide that we hope will become a favourite handbook for anyone starting, developing, troubleshooting, or enhancing mentoring and coaching conversations.

\section{WHO ARE WE?}

This book is drawn on our own practical experience of being academics, academic developers and qualified practicing professional coaches and mentors. Kay has a Masters Degree in Coaching, Mentoring and Leadership Development as well as 10 years' experience designing and enhancing university mentoring cultures at the programme and strategic level. She teaches the professional practices of mentoring, tutoring and supervision and advocates for an embedded 'dialogic approach' at the core of academic practice and staff development. Steve is an independent HE consultant, trainer and coach, with 15 years' experience of working for and with people who work in universities across the world. We combine our complementary experiences here to cover the skills and practices of good coaching and mentoring and offer the benefit of our experience in the Higher Education context, building programmes and institutional strategies for mentoring. 


\section{WHO IS THIS BOOK FOR?}

The ideas we present within this handbook will be of use to anyone interested in supporting others to learn and develop through, around and within their university work. The nature of what constitutes 'development activities' and who occupies the formal or informal 'academic developer' or 'staff developer' role has changed greatly in recent years. One contributing factor to this change is reduced budgets for staff and doctoral researcher development which has created a DIY or 'in-house' response with Departments absorbing the increased workload of meaningful people development. A more pedagogically sound rationale for the expansion of diverse 'developers' is the greater acknowledgement of workplace learning models and peer support, the recognition that institutions have a 'memory' of collective knowledge and learned experiences which is valuable and should be retained, and the emergence of the concept of the informal curriculum for workplace learning. A coaching or mentoring conversation is an ideal mechanism through which valuable learning can take place across all types of university work. Further, the core listening and coaching skills learned and honed as a mentor or coach benefit managers, supervisors and anyone with leadership responsibilities. In this book, we will discuss some of the many applications for coaching-style conversations and unpick the differences in dynamics in these similar roles.

The range of people now interested in the application of mentoring, and coaching conversations for development, now commonly includes professional and academic staff in specialist roles, or nominated leadership roles such as: Department Staff Development Champions, Learning and Teaching Leads, Doctoral Training Centre Managers and Directors, Athena SWAN Convenors, Peer-Observation Scheme Leaders, Postgraduate Research Tutors, Probation 
Mentors, Mentoring Project Officers, Disability Leads, Postgraduate Student Society Chairs, Equality Diversity and Inclusion Officers, each shaping the workplace learning environment. Special recognition is given also to the difficult task of managing mentoring programmes hosted on the national level, by learning and development staff in Professional Societies, and at the Research Councils. Taken as a piece, the landscape for learning through dialogue within universities is rich and complex. This book recognises that complexity and provides guidance and points for consideration that reach beyond the reductive or deficit forms of mentoring.

\section{WHAT IS MENTORING USEFUL FOR?}

Learning through dialogue can be useful on the 1:1 level, as an individual mentoring or coaching conversation with a colleague, team member, mentor, peer or hired professional provider. It can be delivered for example as a defined programme of leadership or executive coaching, as part of 1:1 'catch up' meetings or regular team meetings, during a workshop or programme between peers or through a formal institutional mentoring programme. Coaching skills can also add value in every ad hoc request for a chat, advice or 'brain picking'.

Commonly, when we are offered or seek a coaching or mentoring conversation, it is positioned as a way to discuss and solve a problem. A dialogic approach works well as a problem-solving approach whether the salient matters are ones of navigating snags during a transition to a new role or phase, seeking the next career move or promotion, the need to pick up a new skillset, or finding support for resolving a difficult relationship at work. We stress though that solving problems is not the only positive outcome of coaching or 
mentoring, and these tools should not always be positioned around a perceived deficit of skills or ability. At the individual level, the added value that mentoring and coaching can bring include enhancing the quality of work planning, broadening or widening perspectives and empathy for other viewpoints and the building of new contacts or networks across the institution. Personal gains may also include having your voice heard, gaining confidence, a stronger sense of belonging and job role satisfaction. These gains are applicable to the coach or mentor as well, and we can expect they will also learn through engaging with a conversation or coaching or mentoring partnership. Within teams and line-management relationships, tutoring, and supervision partnerships, a coaching style can increase trust and cohesion. It is an effective way of increasing independence, ownership and proactivity for those you manage, tutor or supervise.

\section{WHEN WE SAY 'COACHING' AND 'MENTORING', WHAT ARE WE TALKING ABOUT?}

In brief, we are talking about two people talking and learning together in a style that draws on the Humanistic principles of working with the whole person, and trusting them to make the choices for themselves, that best fit their development interests. What this looks like in practice is a learning conversation. This conversation may just involve talking together, or they may use a variety of structured processes, styles, conversational tools, worksheets or creative methods to scaffold or enhance that conversation. Wildflower and Brennan (2011) is an excellent resource on styles, tools and how coaches and mentors can use them in practice. For mentoring tools applicable specifically to researchers and research development contexts, see Hopkins, Brooks, and Yeung (2019). 
It's very common to hear that coaching and mentoring are 'similar but different', that they are practices which are related, but not the same. When asked to describe the difference, colleagues with some knowledge of the disciplines will often recite that coaching is shorter term and mentoring more long term. Another comparison often proffered is that mentoring is based in advice-giving and so must be done by a subject expert, but coaching is less directive, and so anyone can coach anyone. Whilst neither of the two previous statements is always wrong, they are also not always right.

We believe that it is more conducive to good practice to talk about the expected skills, attitudes and behaviours that will be required of the coach or mentor within the context of their mentee's learning needs than to offer a universal definition of what coaching or mentoring is. We discuss this further in the opening Chapter of the book. But, for clarity, here is how we position the two sister-disciplines:

- Coaching: A designed, non-directive learning conversation;

- Mentoring: A coaching conversation (larger part) plus some experience-based contextualisation, advice or guidance (smaller part).

In this book, we are positioning coaching and mentoring as specialist educational practices, where the mentor or coach consciously chooses their methods to best meet the learning needs of the coachee or mentee. This includes, for mentors, deciding when to give advice or guidance and when not to. We believe that coaching and mentoring add more value when we situate them within a reflective educational skillset and support mentors and coaches to align their chosen methods with their partner's intended learning or support needs. 


\section{CONVERSIONAL SKILLS AS THE CORE OF MENTORING AND COACHING PRACTICE}

As with all educational practices, there's not a 'right way' to do mentoring, each mentor chooses their own approach, style and practices and applies them in different situations and contexts - but there are certain frameworks into which we fit these choices - and the framework for good practice in mentoring is that we avoid giving advice whenever there's a better way to support our mentee. So, one thing that is common to all mentoring and coaching relationships is that they benefit from being centred on a good quality conversation. Using coaching involves putting aside our tendency to advise, in favour of listening, supporting enquiry, reflection and the raising of self-awareness. Developing a coaching approach means coming back to the Humanistic principles of working with the whole person and trusting them to make the choices for themselves. It all means that you can be helpful even if you've never experienced the precise set of challenges your mentee is experiencing, and it means you can help them learn how to problem-solve for themselves rather than fostering their dependency on you. We cover the pros and cons of this approach, and demonstrate the value of thinking twice before giving advice in Chapter 7.

\section{PERSONAL TUTORING, RESEARCH SUPERVISION, LINE-MANAGEMENT AND TEAM LEADERSHIP}

If mentoring and coaching are supportive learning conversations, what is it that distinguishes them from other one-to-one learning relationships like personal tutoring or research supervision? And if they can be used as part of team meetings, or manager catch-ups, why is mentoring different from management? The answers to these questions again require more of 
us than offering comparative definitions of the roles. Tutoring, supervision, and managerial roles, and the conversations that accompany them are closely related, and they can look very similar, even identical, to coaching or mentoring conversations. Colleagues who have developed their skills by working with mentees report that the knowledge and methods are useful in their other university contexts and that being a mentor has enhanced how they teach, lead teams and how they interact with their research students - it has enabled them to be 'coachlike' or to use a 'mentoring style'. This is a key way in which investing in mentoring has bigger positive effects than simply supporting the learning of the mentees. Mentoring and coaching skills are a good foundation for many of the relationships encountered in the academic environment and have a range of applications; for working with students, peers, teaching teams, research teams and colleagues more widely. We hope you do make use of what you learn from this book to enhance your other relationships with students and colleagues.

Think of the difference between these relationships and coaching or mentoring, as being one of professional distance. A coach or mentor will tend not to have a vested interest in the choices or the development of their mentee. They will not usually, in a university context, be accountable to the organisation for the coachee making progress or for achieving certain goals. They will act as an independent supporter, in their mentee's best interests, but they will not be professionally affected positively or negatively by the choices the mentee makes or the outcomes they achieve. To enable the most effective partnerships for mentoring or coaching, aim to reduce the authority and power differential between the partners, and reduce the potential for a conflict of agendas for the outcomes of the partnership. Some professional distance, or neutrality, is required to enable the most powerful coaching and mentoring. 


\section{ISN'T THIS COUNSELLING? IT CERTAINLY FEELS THERAPEUTIC}

As with the professional partnerships described above, there are similarities between the styles of conversation used in mentoring and coaching and some commonly used styles of counselling and therapy. This is to be expected as they have common roots in Humanism and the humanistic style of personal learning and growth through conversation (see Chapter 5). Additionally, they look similar in practice as a lot of the tools and styles established for therapeutic use have been appropriated into coaching and mentoring because they are effective. For an excellent deep resource on the philosophies and tools of Coaching Psychology, do take up Cox, Bachkirova, and Clutterbuck (2010) listed in our recommended reading section.

It is common and absolutely okay that mentees and coachees would feel and express some emotional relief from getting their concerns out in the open, from the excitement of new learning, from acknowledging a mistake that they have made, from recounting a difficult situation or from making a decision they have been struggling with. However, coaching and mentoring are not counselling or therapy, because the context for the learner, and their learning needs are different. In mentoring and coaching, we are not working with people in a significant and prolonged state of distress. Nor are we working with people with persistent patterns of significant unhelpful or detrimental behaviour. It requires the mentor or coach to draw a boundary between the two and resist temptation to overstep that boundary. Chapter 22 offers more detail on how to recognise when that boundary has been approached and offers guidance on what you can usefully do and say in the moment, to support your coachee or mentee to seek additional specialist support. 


\section{STRUCTURAL INEQUALITIES CAN'T BE COACHED}

\section{AWAY}

It's important to recognise that in this book we are not advocating that coaching, mentoring, positive thinking, or a 'can do' attitude, can overcome systemic structural barriers, career bottlenecks and well-documented gender, disability and ethnicity inequalities. We recognise that career success and progression is dependent on more than a good conversation and effective planning. A lack of opportunities, casualisation of work, refusal of access or permission and outright discrimination cannot be overcome by the actions of a good mentor. It is important, given rising pressures on academic staff and emerging evidence of universities as poor mental health hotspots, that this book and your practice as a coach or mentor should be appreciative of the complexities of inequality. While we must all take responsibility for our development, we cannot place full responsibility on the individual to overcome or solve systemic issues.

\section{HOW TO USE THIS BOOK}

We wanted to write a book that supports staff in universities who are tasked with being a coach or mentor, or with initiating or developing a coaching or mentoring initiative, pilot scheme or large-scale programme. We work with and are contacted frequently by colleagues who work in universities asking us to suggest coaching approaches or tools, for guidance on mentoring programme design and practice, and with requests for help by mentees and mentors who are in mentoring situations that aren't working or could be better. We wanted to produce a handbook that shares the answers to these FAQs more widely, rolling all our guidance and 
experience into one place. In doing so, we have also created a resource mentoring Programme Leaders who are about to get started, or who want to enhance their work, that helps you to work through the planning and development of a good mentoring offer, that places coaching conversations at the heart of practice.

Whilst this book is the result of 10 years and more of critical practice and research into the area, we do not present here a critical analysis of the coaching and mentoring literature. We recognise that you are likely to want to get your own practice or programme started sooner rather than later, and so we offer you a way of doing that. As is established practice, where we make specific claims, we will signpost you to the original resource or research. We are also drawing on our own deep experience in coaching and of supporting coaches, mentors and programmes. We uncover the often-unseen factors that contribute to effective mentoring and successful inhouse mentoring programmes. From the skills, practices and continued development of the mentors to the dynamics of the partnership and the careful matching of the pairs, and crucially, the positioning of mentoring (purpose, prestige, value) in the organisation including the support and supervision of staff who mentor, which are all the responsibility of Programme Leaders.

We offer the ideas within this book, in a coaching style. The ideas presented here work for us and for our learners. You are free to select what you need, adapt those ideas that need more tailoring to your context and reject what does not resonate with you and your work. We would be delighted to see you continue to shape and develop the ideas we ourselves have shaped and developed in these pages.

- Section 1 covers where to start, surveying the landscape for developing people within university contexts and 
understanding and building the foundations for deploying a mentoring approach within your organisation.

- Section 2 includes specific practices, concepts, tools, exercises and ideas that you can deploy as coaches and mentors yourself, or for coaches and mentors you support in the programmes you lead.

- Section 3 takes a bigger picture look at enhancing the practice, value and reputation of mentoring at the programme level and in developing a strategic approach to understanding the impact of mentoring.

\section{RECOMMENDED READING}

Below, we offer you a selection of our favourite literature, sources that complement our book, and will give you pathways in to the wider literature.

Andreoff, J. (2016). Coaching and mentoring in higher education: A step-by-step guide to exemplary practice. London: Red Globe Press.

Bell, A., \& Treleaven, L. (2011). Looking for professor right: Mentee selection of mentors in a formal mentoring program. Higher Education, 61(5), 545-561. doi:10.1007/s10734-0109348-0

Brace, J. L., Baiduc, R. R., Drane, D. L., Flores, L. C., Beitel, G. J., \& Lo, S. M. (2018). Design, implementation, and evaluation of a multi-disciplinary professional development program for research mentors. Mentoring \& Tutoring: Partnership in Learning, 26(4), 377-399. doi:10.1080/13611267.2018. 1530101

Bridges, W. (2003). Managing transitions: Making the most of change. New York, NY: Perseus.

Brock, V. G. (2012). Sourcebook of coaching history. Scotts Valley, CA: CreateSpace Independent Publishing Platform.

Cox, E., Bachkirova, T., \& Clutterbuck, D. (Eds.). (2010). The complete handbook of coaching. London: SAGE Publications.

Daniel, A., Franco, S., Schroeder, N. L., \& Cenkci, A. T. (2019). Cross-cultural academic mentoring dyads: A case study. Mentoring \& Tutoring: Partnership in Learning, 27(2), 164-189. doi:10.1080/13611267.2019.1611286 
Dawson, P. (2014). Beyond a definition: Toward a framework for designing and specifying mentoring models. Educational Researcher, 43(3), 137-145. doi:10.3102/0013189X145 28751

Downey, M. (2002). Effective coaching. London: Texere.

Gardiner, M., \& Kearns, H. (2012). The ABCDE of Writing: Coaching high-quality high-quantity writing. International Coaching Psychology Review, 7(2), 237.

Godskesen, M., \& Kobayashi, S. (2015). Coaching doctoral students - a means to enhance progress and support selforganisation in doctoral education. Studies in Continuing Education, 38(2), 145-161. doi:10.1080/0158037X.2015. 1055464

Graham, C. (2019). Literature review: The gap between mentoring theory and practice for diverse women faculty. Mentoring \& Tutoring: Partnership in Learning, 27(2), 131-143. doi:10.1080/13611267.2019.1611273

Hawkins, P., \& Smith, N. (2011, 2013). Coaching, mentoring and organizational consultancy: Supervision and development. Maidenhead: Open University Press.

Hopkins, S., Brooks, S., \& Yeung, A. (2019). Mentoring to empower researchers. London: SAGE Publications.

Horowitz, J., \& Christopher, K. B. (2013). The research mentoring program: Serving the needs of graduate and undergraduate researchers. Innovative Higher Education, 38(2), 105-116. doi:10.1007/s10755-012-9230-3

Hudson, P. (2013). Mentoring as professional development: "growth for both" mentor and mentee. Professional Development in Education, 39(5), 771-783. doi:10.1080/ 19415257.2012.749415

Kensington-Miller, B. (2017). Surviving the first year: New academics flourishing in a multidisciplinary community of practice with peer mentoring. Professional Development in Education, 44(5), 678-689. doi:10.1080/19415257.2017. 1387867

Kroll, J. (2017). Requisite participant characteristics for effective peer group mentoring. Mentoring \& Tutoring: Partnership in Learning, 25(1), 78-96. doi:10.1080/13611267.2017.13 08096 
Langdon, F. J. (2017). Learning to mentor: Unravelling routine practice to develop adaptive mentoring expertise. Teacher Development, 21(4), 528-546. doi:10.1080/13664530.2016. 1267036

Lech, A. M., van Nieuwerburgh, C., \& Jalloul, S. (2017). Understanding the experience of $\mathrm{PhD}$ students who received coaching: An interpretative phenomenological analysis. Coaching: An International Journal of Theory, Research and Practice, 11(1), 60-73. doi:10.1080/17521882.2017.1381753 Lewis, C., \& Olshansky, E. (2017). Relational-cultural theory as a framework for mentoring in academia: Toward diversity and growth-fostering collaborative scholarly relationships. Mentoring \& Tutoring: Partnership in Learning, 24(5), 383-398. doi:10.1080/13611267.2016.1275390

Lindén, J., Ohlin, M., \& Brodin, E. M. (2013). Mentorship, supervision and learning experience in $\mathrm{PhD}$ education. Studies in Higher Education, 38(5), 639-662. doi:10.1080/03075079. 2011.596526

Mullen, C. A., \& Hutinger, J. L. (2009). At the tipping point? Role of formal faculty mentoring in changing university research cultures. Journal of In-Service Education, 34(2), 181-204. doi:10.1080/13674580801951012

Nicholson, L. J., Rodriguez-Cuadrado, S., \& Woolhouse, C. (2018). Reframing peer mentoring as a route for developing an educational community of practice. Mentoring \& Tutoring: Partnership in Learning, 26(4), 420-440. doi:10.1080/ 13611267.2018.1530163

Quinlan, E., Crowe, T., Deane, F. P., \& Whittington, M. (2019). Functions of peer mentoring, satisfaction and the "real" relationship in postgraduate psychology education. International Journal of Mentoring and Coaching in Education, 8(1), 52-68. doi:10.1108/IJMCE-06-2018-0033

Rosinski, P. (2003). Coaching across cultures: New tools for leveraging national, corporate, and professional differences. London: Nicholas Brealey Pub.

Skiffington, S., \& Zeus, P. (2003). Behavioural coaching: Building sustainable personal and organizational strengths. New York, NY: McGraw-Hill.

Starr, J. (2016). The coaching manual: The definitive guide to the process and skills of personal coaching (4th ed.). London: Pearson Business. 
Thomas, J. D., Lunsford, L. G., \& Rodrigues, H. A. (2015). Early career academic staff support: Evaluating mentoring networks. Journal of Higher Education Policy and Management, 37(3), 320-329. doi:10.1080/1360080X.2015.1034426

Turner, R., Huang, R., Poverjuc, O., \& Wyness, L. (2016). What role do teaching mentors play in supporting new university lecturers to develop their teaching practices? Professional Development in Education, 42(4), 647-665. doi:10.1080/ 19415257.2015.1065898

Weisblat, G., \& Sell, C. (2012). An exemplar in mentoring and professional development: Teaching graduate students transferable skills beyond the discipline. Journal of Research Administration, 43(1), 60-84.

Wildflower, L., \& Brennan, D. (2011). The handbook of knowledge-based coaching: From theory to practice. Hoboken, NJ: John Wiley \& Sons. 
This page intentionally left blank 
SECTION 1 
This page intentionally left blank 


\section{1 \\ COACHING AND MENTORING: CONCEPTS AND TERMINOLOGIES EXPLORED}

One of the themes that runs through the policy and advisory position papers about professional development in the Higher Education (HE) sector is the recommendation of mentoring (or access to a mentoring scheme) as a core tool to help individuals progress. Presumably, although this is often not explicitly stated, such direction is to facilitate people in learning from their experiences and help them to plan. Yet simultaneous feedback from research and academic students and staff at grass-roots levels repeatedly suggests that they find it difficult or even impossible to hold meaningful conversations of this kind with the colleagues who are commonly available to them, their Principal Investigators or supervisors. Reasons for this non-alignment within the line management relationship may include time and pressure to publish now, at the cost of longer-term development; a lack of empathy or inclination on the part of the manager; or a lack of proactivity on the part of the researcher. Universities, 
then, have sought to broaden this pool of supporting others, by providing mentors outside the direct supervision relationships. Yet, a lack of clarity about what a mentor is or does, and what is involved in good mentoring, hamper those involved and decrease the effectiveness of a well-intentioned initiative.

As development professionals and qualified coaches, we are both well-drilled in the notion that effective learning design should start by addressing the question of 'Why?' defining the learning need. Our audiences and stakeholders, we're told, need to understand the rationale behind the activities on offer, so they can fully engage with the information and methodologies that are presented. In the case of this book, the 'why?' questions would include, but not be limited to:

- Why use coaching or mentoring as a professional development tool?

- Why do people seek out and benefit from personalised development through coaching or mentoring?

- Why do development professionals claim that coaching and mentoring is so effective as a tool?

However, such questions aren't much help if we don't clarify what coaching and mentoring means, both as abstract and intellectual terms but also as practical entities in a landscape where the line between them is often blurred to a point of non-existence. When training to be coaches, we were introduced to the idea of coaching as 'a conversation with a purpose', and we have subsequently seen this idea applied widely. While technically accurate, it is not, quite refined enough to be helpful to a new coach or mentor. After all, 'Can I buy some bananas?' - 'Yes, how many would you like?' is a 
conversation with a purpose, but it is neither coaching nor mentoring.

In this book, we are positioning coaching and mentoring as specialist educational practices, where the mentor or coach consciously chooses their methods to best meet the learning needs of the coachee or mentee.

Like 'teaching', 'managing' or 'leading' the terms mentoring, and coaching can be understood, and defined very differently depending on the participants' prior experiences of those labels, the people involved, the conventions of the workplace or subject area, and the tasks to be completed. Consider how the role of the 'mentor' might differ in mentoring partnerships, for example: for a new postgraduate student transitioning to doctoral research; for a senior leader in Library Services taking on executive responsibility; for a new member of the front desk team in Student Accommodation Services; or for an established Senior Lecturer seeking to learn how to write a $4 *$ Impact case study for the Research Excellence Framework. One label, for four different sets of role expectations.

\section{COACHING OR MENTORING?}

Within the field of people development there are seemingly endless and, we believe largely pointless, debates as to defining what constitutes coaching and separating it from what constitutes mentoring. Indeed, just within the field of professional 'coaching', there are myriad understandings and formulations of what the job actually entails - ranging from very directive sports, skills, business or exam coaching at one end of the spectrum through to the various interpretations of holistic 'life' coaching. Many of the more ephemeral interpretations of 
coaching are, we would offer, not particularly trusted or seen as valuable within the academic community and certainly, as an external coach, one of the questions we are asked by potential academic clients is 'what experience do you have of the University environment?'. Thus, by proxy, the expectation of 'coaching' strays into territory that many would label as 'mentoring' - one based in experience of the mentee's context and profession.

There is a great deal of literature available on coaching and mentoring and the overlap between the two (recommended key works include: Garvey, Stokes, and Megginson (2014), Megginson and Clutterbuck (2005) and the Harvard Business School - Essentials guide (2014)). But many of the published definitions of coaching and mentoring, especially the online material with a corporate focus, sit out of alignment with ours. For instance, we often read words to the effect that a mentor is 'always self-selected by an individual', whereas a coach is always provided by the organisation. This is certainly not our experience within the HE sector. We frequently read that coaches 'steer an individual towards a preordained goal', whereas mentors are more general and perhaps genial sounding boards. Again, this is not our experience. The desire within the sector, certainly within teaching, research, and academic staff and students seems to be for mentors who both understand the context and challenges of the environment (as opposed to a professional coach who can simply ask the 'right' questions) and who also knows how to carefully use coaching tools and techniques with someone, so they can focus on setting and achieving worthwhile and compelling goals. A mentor, who deploys a coaching style.

We believe that it is more conducive to good practice to talk about the expected skills, attitudes and behaviours that will be required of the coach or mentor within the context of 
their mentee's situation and learning needs, than to offer a universal definition of what coaching or mentoring is. However, we do want to start by offering a working definition of both coaching and mentoring, in order that we can build on this base of understanding throughout the book. We have purposefully not sought to offer separate definitions of coaching, and of mentoring, as for those new to these specialist practices, it is more helpful to think about their huge similarities. We hope the statement below provides you with some useful points to consider:

A designed conversation to aid the clarification and achievement of an individual's goal(s) and to belp them capture the learning obtained in the process of doing so.

Furthermore, for clarity, here is how we position the two sister-disciplines:

- Coaching: a designed, non-directive learning conversation

- Mentoring: A coaching conversation (larger part) plus some experience-based contextualisation, advice or guidance (smaller part).

While not explicit in our definition and positioning above, we want to advise from the outset against any language that could lead new mentors or coaches towards two oft-cited misconceptions of the role of the coach or mentor (these and other misconceptions are considered in detail in Chapter 24).

Firstly, that mentoring or coaching is a replacement for the role that should be played by an effective line manager. This should not be the case and we advocate making this clear to your mentees, coachees or trainee mentors. 
Secondly, that mentoring and coaching are applied to fulfil a deficit or weakness on the part of the person being coached or mentored. We are of the opinion that these practices should provide a way of helping an individual to learn, develop and grow. They should not be seen as ways of 'fixing' an individual or serving to take the place of remedial performance management - although this is the reason, it seems, for which many Human Resources (HR) Departments seek to apply it as a tool.

Aligned with our definition and positioning, a coach or mentor will essentially support a cyclical process of learning, reflection and planning (see also Chapter 5). The key unifier here, that binds coaching and mentoring as development processes, is that they both centre on an individual's learning. They enable the individual to be conscious about what they what to learn, what they are learning, how they have developed and how they are capable of using that learning in a transferable way. We will return to this notion of learningcentred development repeatedly throughout this book.

If we examine what allows an individual to achieve a learning objective, there are three key elements a mentor or coach can support, choosing tools and techniques as appropriate. We believe that both coaching and mentoring have potentially a key and powerful role to play in all three elements:

- Clarity: Does the individual actually know what it is that they want and why the goal is personally important to them (as opposed to any other stakeholder, organisation or actor)?

- Capability: Does an individual have the requisite skills and resources to achieve their goal or the means to gain them?

- Confidence: Does an individual believe that they can achieve their goal? This element of mentoring is particularly 